\title{
Burden of pelvic organ prolapse in Ethiopia: a systematic review and meta- analysis
}

Getnet Gedefaw ${ }^{1,2^{*}}$ (D) and Asmamaw Demis ${ }^{1,2}$

\begin{abstract}
Background: Pelvic organ prolapse can significantly affect a woman's quality of life by compromising physical, social, psychological and sexual function. Pelvic organ disorders and its consequences have higher economic burden to the patient as well to the country. Therefore, this systematic review and met- analysis aimed to estimate the burden of POP in Ethiopia.

Methods: International databases (MEDLINE/Pub Med, Hinari, Scopus, Google scholar, African journals and literatures were searched and seven eligible cross sectional and two case control studies were included in this systematic review and meta-analysis. Eggers test and funnel plot were computed to check publication bias across the studies. Publication bias was computed using a funnel plot and eggers test. Heterogeneity of the studies was checked using Cochrane Q-test and $\mathrm{I}^{2}$ statistic. Subgroup analysis was computed for the evidence of heterogeneity.

Results: This systematic review and meta-analysis revealed that the overall national prevalence of pelvic organ prolapse in Ethiopia was 23.52\% (95\% Cl: 61.04, 80.24). Being rural resident (AOR $=3.29 ; 95 \% \mathrm{Cl}: 1.38-7.85), \mathrm{I}^{2}=$ $47.5 \%, P=0.167)$, having < 18.5 BMI (AOR $\left.=2.59 ; 95 \% \mathrm{Cl}: 1.53-4.4), \mathrm{I}^{2}=59.9 \%, P=0.64\right)$, and age $>40(\mathrm{AOR}=7.43$; $\left.95 \% \mathrm{Cl}: 2.27-24.29), I^{2}=75.9 \%, P=0.016\right)$ were the associated risk factors for pelvic organ prolapse.

Conclusions: The pooled prevalence of pelvic organ prolapse was high. Residence, body mass index and age of the women were the predictors of pelvic organ prolpase. Creating awareness and identifying the modifiable and non modifiable risk factors for pelvic organ prolpase is a crucial strategy to prevent further complications and risk of operation.
\end{abstract}

Keywords: Pelvic floor disorders, Systematic review, Meta-analysis

\section{Background}

Pelvic organ prolapse is a complex condition resulting from the weakness and defects of pelvic floor structures. Pelvic organ prolapse (POP) is the descent of one or more aspects of the vagina and uterus: the anterior vaginal wall, posterior vaginal wall, the uterus (cervix), or

\footnotetext{
* Correspondence: gedefawget@gmail.com

'Department of Midwifery, College of Health Sciences, Woldia University, P.O.Box: 400, Woldia, Ethiopia

${ }^{2}$ Department of Nursing, College of Health Sciences, Woldia University,

P.O.Box: 400, Woldia, Ethiopia
}

the apex of the vagina (vaginal vault or cuff scar after hysterectomy) [1].

Worldwide, millions of women have been affected by pelvic floor disorders. One in every nine American women will undergo surgery for a pelvic floor disorder in her lifetime, with $30 \%$ of women having a chance of requiring additional surgery for the same condition $[2,3]$.

Pelvic organ prolapse occurs when the pelvic floor no longer supports the proper positioning of the pelvic organs, i.e. the vagina, bladder, rectum or uterus. In unites states of America, around $6-7 \%$ of the women having

C C The Author(s). 2020 Open Access This article is licensed under a Creative Commons Attribution 4.0 International License, which permits use, sharing, adaptation, distribution and reproduction in any medium or format, as long as you give appropriate credit to the original author(s) and the source, provide a link to the Creative Commons licence, and indicate if changes were made. The images or other third party material in this article are included in the article's Creative Commons licence, unless indicated otherwise in a credit line to the material. If material is not included in the article's Creative Commons licence and your intended use is not permitted by statutory regulation or exceeds the permitted use, you will need to obtain permission directly from the copyright holder. To view a copy of this licence, visit http://creativecommons.org/licenses/by/4.0/. The Creative Commons Public Domain Dedication waiver (http://creativecommons.org/publicdomain/zero/1.0/) applies to the data made available in this article, unless otherwise stated in a credit line to the data. 
pelvic floor disorders were experiencing pelvic and urinary symptoms. Feeling of vaginal bulging and/or pelvic pressure, urinary incontinence, and constipation has been identified as symptoms of pelvic organ prolapse [4-6]. In different countries, the number of admissions for POP surgery was significantly increasing; for instance, the rate of admission for POP surgery per 1000 women 0.87, 1.14, 1.13 in Germany, France, and England respectively [7]. The estimated prevalence of pelvic organ prolapse (POP) has been reported with a figure of nearly $9 \%$, however, the burden of POP in low and middle income countries particularly in Sub Saharan African countries is still challenging. Moreover, the prevalence of POP in low income countries is much more increasing which recently has been reported to be around $20 \%[8,9]$.

POP and its complications make an impact on a considerable economic burden on the affected person. About $11 \%$ of the American women undergo surgery for POP or incontinence before the age of 79 , with $29.2 \%$ of the women having a chance of requiring additional surgery [10].

Pelvic organ prolapse is highly prevalent among women with the age of over 40 years old, geriatric women, and postmenopausal women with the estimated prevalence of $41-50 \%$ [11, 12].

As different studies, in low and middle income countries showed the mean of pelvic organ prolaps is $19.7 \%$ with the estimated range from 3.4 to $56.4 \%$. Moreover, most studies were small and not population based, as a result methods of ascertaining of POP and definitions have been varied [9].

High parity, older age, obesity, pregnancy and vaginal delivery, menopause, constipation, persistent coughing, early age at first delivery, forceps delivery, prolonged second stage labor, and prolonged heavy lifting are the revealed contributing factors to cause strain to the pelvic floor. The global burden of Pelvic floor disorder is increasing due to increasing the age of the population [13].

The symptoms pelvic floor disorders had affect many aspects of a woman's life, such as social, psychological, occupational, domestic, physical, cognitive, behavioral and sexual domains. In general, pelvic floor disorders have a negative impact on women's lives, emotional and quality of life. Certainly, POP may be associated with a variety of systemic symptoms such as urinary, bowel and sexual symptoms which may significantly confrontation the quality of life of the women have been facing different mental and psychological illness such as mood and personal disorders [14, 15].

In Ethiopia, institutional delivery is limited, high fertility rates and higher rates of gynecologic disease have been reported and only $48 \%$ of women deliver in health institutions [16].

In Ethiopia, there is no any take apart strategy to prevent and manage pelvic floor disorders both in private and governmental health institutions. Even if, different single studies have been tried to identify the types and levels of pelvic floor disorders, there has been limited source of evidence regarding types, and burdens of POP in Ethiopia. As a result, this study helps to estimate the national burden of Pelvic organ prolapse at national level to design appropriate preventions and management modalities.

\section{Methods}

This systematic review and meta-analysis were conducted to estimate the national burden of POP and its associated factors in Ethiopia using the standard PRIS MA checklist guideline.

\section{Searching strategy}

International databases (MEDLINE/Pub Med, Hinari, Scopus, Google scholar, African journals and literatures) were searched and included in this study. Searching terms were used using PICO formulating questions. The following Searching terms were used: pelvic floor disorders, POP, utero-vaginal prolapse, vault prolapse, rectocele, cystocele AND Ethiopia and related terms.

\section{Eligibility criteria \\ Inclusion criteria}

Study design Observational studies (cross-sectional, cohort and case-control) were included.

Study area Only studies conducted in Ethiopia without time limiting and reported the prevalence or at least one least adjusted associated factor of pelvic organ prolapse were included.

Publication status and language Only English language articles both published and unpublished reported studies were included.

\section{Exclusion criteria}

Articles without full abstracts or texts and articles reported out of the outcome interest were excluded.

\section{Quality assessment}

After collecting the findings from all databases, the articles were exported to Microsoft Excel spreadsheet. Two authors (GG \& AD) independently extracted the data and reviewed the screened and eligible articles. Any disagreement was handled by the two reviewers (GG \& $\mathrm{AD})$. Finally, a consensus was reached between two 
authors through discussion. The methodological quality of each study (sampling strategy, response rate, and representativeness of the study), comparability and outcome were checked using the NOS tool. Newcastle-Ottawa Quality Assessment Scale (NOS) for cross sectional and case control studies were used to assess the methodological quality of a study and to determine the extent to which a study has addressed the possibility of bias in its design, conduct and analysis. All of the included articles scored (NOS) 7 and more can be considered as "good" study with low risk (Table S1).

\section{Measurement of outcome}

In this study measurement of outcome was measured and included from studies report POP depending on either POP-Q stage or the traditional classification of POP.

\section{POP-Q stage}

Stage-0 "no prolapse"

Stage I is when the most distal portion (leading surface) of the prolapse is $1 \mathrm{~cm}$ above the level of the hymen $(,-1 \mathrm{~cm})$

Stage II is when the most distal portion (leading edge) of the prolapse is $\# 1 \mathrm{~cm}$ proximal to or extends $1 \mathrm{~cm}$ through the plane of hymen $(\$-1 \mathrm{~cm}$, but \#+1 cm) Stage III is when the most distal portion of the prolapse is $.1 \mathrm{~cm}$ below hymen but no further than 2 $\mathrm{cm}$ less than the TVL (there is no complete vaginal eversion)

Stage IV is when there is complete eversion of the total length of the pelvic organ, meaning the pelvic organ protrudes at least the total vaginal length minus $2 \mathrm{~cm}$ beyond the hymen.

\section{Traditional classification of POP}

1st: Descent within the vagina

2nd: Descent to the introitus

3rd: Descent outside the introitus

Pelvic organ prolapse Any pelvic disorder at least reported any of one of the pelvic floor disorders (utero-vaginal prolapse, rectocele, cystecole, vault prolapse) with any stages were considered as the primary outcome of the study.

Anterior compartment prolapse (cystocele) Hernia of anterior vaginal wall often associated with descent of the bladder.

Posterior compartment prolapse (rectocele) Hernia of the posterior vaginal segment often associated with descent of the rectum.
Apical compartment prolapse (uterine prolapse, vaginal vault prolapse) Descent of the apex of the vagina into the lower vagina, to the hymen, or beyond the vaginal introitus.

\section{Data extraction}

Micro-soft Excel (2016), and STATA version 11 software were used for data entry and analysis respectively. Two authors (AD and GG) independently extracted all the important data using a standardized JBI data extraction format. Substantial agreement between reviewers i.e. Cohen's kappa coefficient $>0.60$ were accepted. Any disagreement between reviewers was resolved through discussion and then consensus was reached. During data extraction; name of the author, sample size, publication year, study design, prevalence, response rate, population outcome, study site, and different contributing factors were included. Moreover, prevalence of pelvic organ prolapse with $95 \% \mathrm{CI}$ and associated factors were collected [17].

\section{Data analysis}

Egger's regression test and funnel plot were computed to check the publication bias across and within the studies. Cochrane Q-test and I-squared statistic were used to check the heterogeneity of studies [18]. Pooled analysis was computed using a weighted inverse variance random-effects model [19]. Subgroup analysis was done by study setting, study region and year of publication. The data were analyzed and presented using STATA version 11 statistical software and forest plot respectively. The pooled prevalence of POP was expressed with $95 \% \mathrm{Cl}$, where as a $\log$ odds ratio was used to declare the association between associated factors and POP [17].

\section{Results}

Characteristics of the included studies

238 articles were retrieved using a search strategy about pelvic organ prolapse and associated factors in Ethiopia using online international datasets such as; MEDLINE/ PubMed, Hinari, Scopus, Google scholar, African journals and literatures. After duplicates were removed, 117 studies remained.

68 articles were excluded after review of their titles and abstracts from the remaining 117 articles. Therefore, 49 full-text articles were accessed and assessed for inclusion criteria, resulting further exclusion of 40 articles primarily due to reasons (Fig. 1). As a result, 9 studies were fulfilled the inclusion criteria to undergo the final systematic review and meta-analysis (Table 1).

\section{Magnitude of pelvic organ prolapse in Ethiopia}

The overall burden of pelvic organ prolapse is presented with a forest plot (Fig. 2). Therefore, the national 


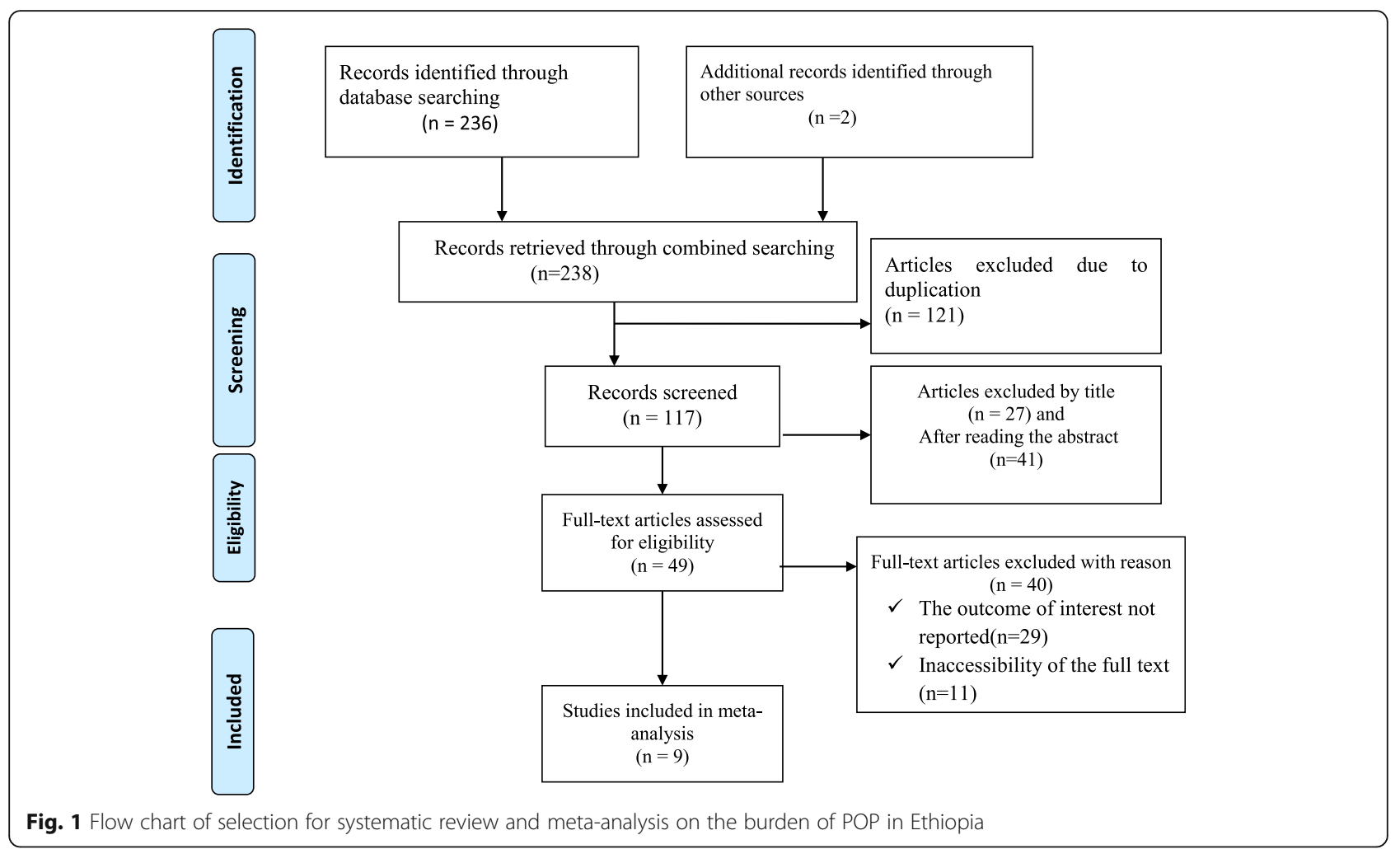

estimated prevalence of pelvic organ prolapse in Ethiopia was $23.52 \%$ (95\% CI: $14.3-32.74 ; \mathrm{I}^{2}=98.4 \%, P<0.001$ ).

\section{Publication bias}

Funnel plot was assessed for asymmetry distribution of pelvic organ prolapse by visual inspection (Fig. 3). Egger's regression test showed a $p$-value of 0.967 with no evidence of publication bias.

\section{Subgroup analysis}

Subgroup analysis was employed with the evidence of heterogeneity. In this study, the Cochrane $\mathrm{I}^{2}$ statistic was 98.4\%, $P<0.001$, which showed the evidence of marked heterogeneity. Therefore subgroup analysis was done using study region and study design. As a result, the burden of pelvic organ prolapse was highest in Northern part of Ethiopia $99.2 \%$ whereas $88.7 \%$ in the study conducted with facility based setting (Table 2).

\section{Factors associated with pelvic organ prolapse in Ethiopia}

In this study, having body mass index $(\mathrm{BMI})<18.5$, being rural resident and having age of the women $>40$ years were the determinants factors of pelvic organ prolapse.

The odds of having pelvic organ prolapse were $(\mathrm{AOR}=$ 3.29; 95\% CI: $\left.1.38-7.85), \mathrm{I}^{2}=47.5 \%, P=0.167\right) 3.29$ times prevalent among women who resided in rural areas than those who were living in urban areas (Fig. 4).

Table 1 Study characteristics included in the systematic review and meta-analysis on the burden of POP in Ethiopia

\begin{tabular}{|c|c|c|c|c|c|c|}
\hline Authors & Region & Study setting & Study design & Sample size & Prevalence & Quality \\
\hline Tsegay B [20] & Tigray & Facility based & Cross-sectional & 370 & NA & Low risk \\
\hline Asresie et al. [21] & Amhara & Facility based & Case control & 1676 & 42.3 & Low risk \\
\hline Andualem Henok [22] & SNNPR & Facility based & Cross-sectional & 422 & 13.27 & Low risk \\
\hline Berihun et al. [23] & Amhara & community based & Cross-sectional & 395 & 11.9 & Low risk \\
\hline Dheresa et al. [24] & Oromia & Community based & Cross-sectional & 3432 & 20.5 & Low risk \\
\hline Menur A. et al [25] & Oromia & Facility based & Cross-sectional & 129 & 40.7 & Low risk \\
\hline Lukman [26] & AA & Facility based & Cross-sectional & 195 & 17.2 & Low risk \\
\hline Lukman [26] & Amhara & Facility based & Cross-sectional & 156 & 19.9 & Low risk \\
\hline Zinash et al. [27] & SNNPR & Facility based & Case control & 318 & NA & Low risk \\
\hline
\end{tabular}




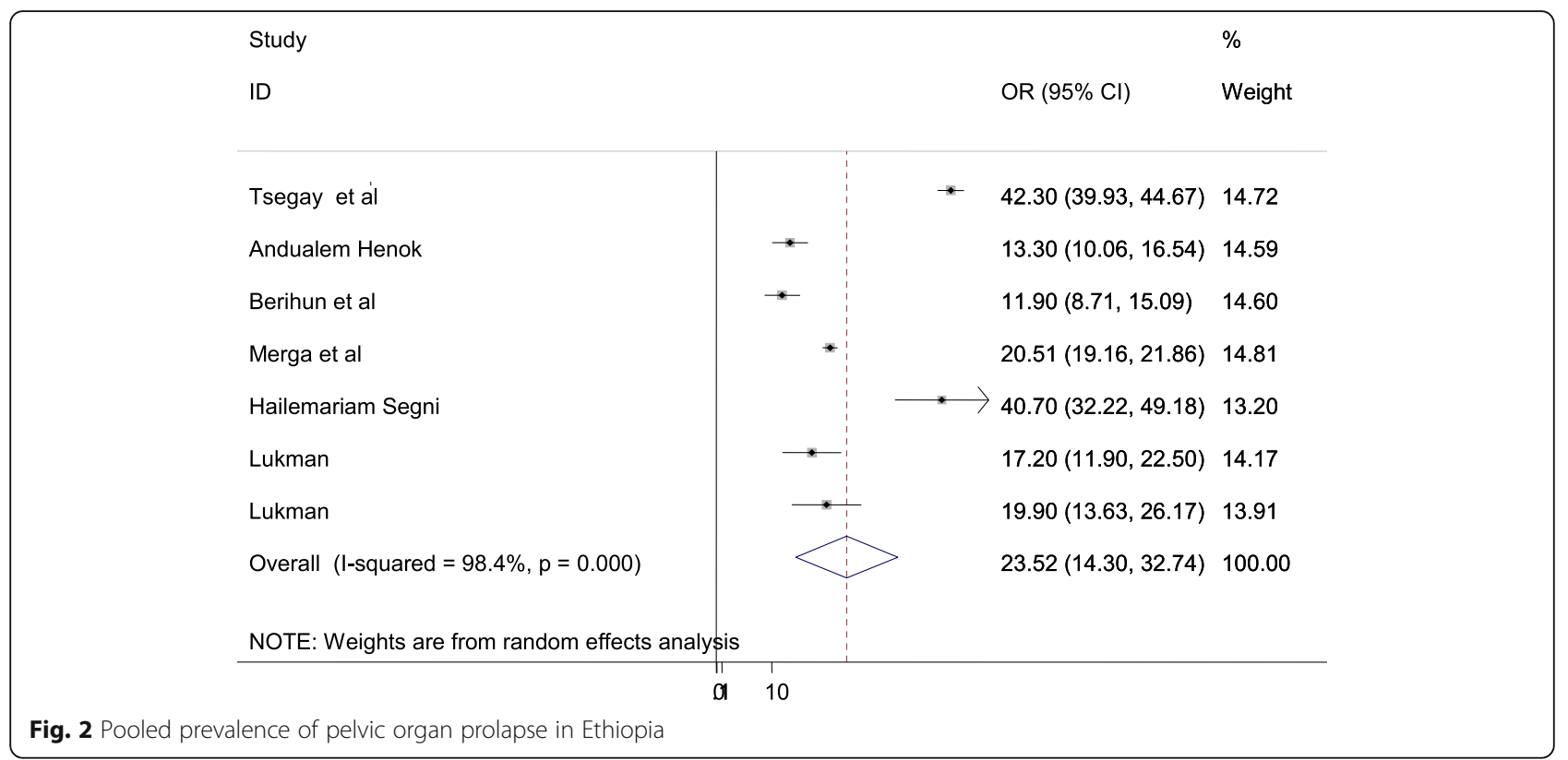

The odds of having pelvic organ prolapse were 7.43 $\left.(\mathrm{AOR}=7.43 ; 95 \% \mathrm{CI}: 2.27-24.29), \mathrm{I}^{2}=75.9 \%, P=0.016\right)$ times more likely among women having more than 40 years old than the younger population (Fig. 5).

The chance of having pelvic organ prolapse were $\left.(\mathrm{AOR}=2.59 ; 95 \% \mathrm{CI}: 1.53-4.4), \mathrm{I}^{2}=59.9 \%, P=0.64\right)$, 2.59 times more likely among women who have less than 18.5 body mass index than the counterparts (Fig. 6).

\section{Discussion}

In this meta-analysis, the national magnitude of pelvic organ prolpase in Ethiopia was 23.52\% (95\% CI: 14.3-
32.74; $\left.\mathrm{I}^{2}=98.4 \%, P<0.001\right)$. The finding of this study is consistent with the study done in China [28], accounts 2962 out of 20,008 women, estimated as $14.8 \%$. This might be due to both of our study and the study conducted at China were involving large sample size as a result, increasing the sample size may increase the precision and the accuracy of the data.

The finding of this study is lower than the study done in Tanzania [29], and Gambia [30]. This highest magnitude might be justified as studies used different outcome measurements; such as, different methods of POP classification, inclusion of different age groups, and

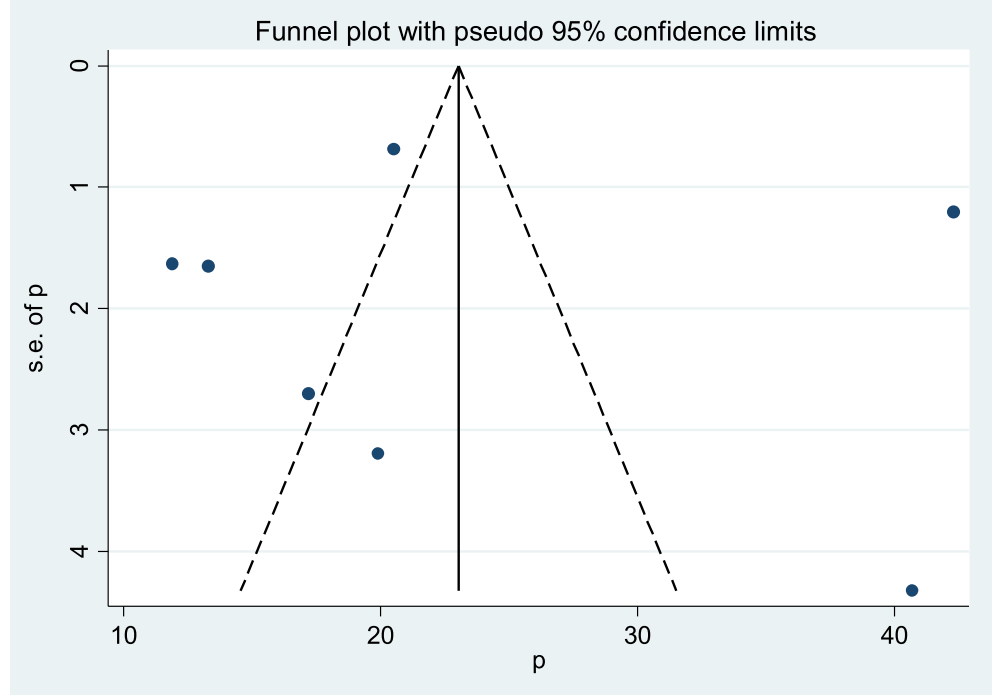

Fig. 3 Funnel plot showed publication bias for pelvic organ prolapse 
Table 2 Subgroup analyses on the burden of pelvic organ prolapse in Ethiopia, 2019)

\begin{tabular}{|c|c|c|c|c|c|}
\hline Variables & Subgroup & No. of studies & Prevalence $(95 \% \mathrm{Cl})$ & $1^{2}(\%)$ & $P$-value \\
\hline \multirow[t]{2}{*}{ Sample design } & Facility based & 5 & $16.45(12.12-20.78)$ & 88.7 & $<0.001$ \\
\hline & community based & 2 & $42.18(39.91-44.46)$ & 0 & $<0.722$ \\
\hline \multirow[t]{3}{*}{ Study area } & South East Ethiopia ${ }^{a}$ & 2 & $14.66(11.02-18.31)$ & 34 & 0.218 \\
\hline & Oromia & 2 & 30.15 (10.39-49.92) & 95.3 & $<0.001$ \\
\hline & Northern Ethiopiab & 3 & $24.75(2.67-46.83)$ & 99.2 & $<0.001$ \\
\hline
\end{tabular}

${ }^{\mathrm{a}}$ Addis Ababa \& South nations nationalities and people, ${ }^{\mathrm{b}}$ Amhara \& Tigray

considering rural and urban resided women with different cultures and perceptions. Besides, this might be due to this systematic review and meta-analysis included studies done on nearly all institutional settings, as a result the tendency to face the burden in urban areas may be lower due to the availability and accessibility of health sectors, health professionals and mass media as a result the knowledge towards pelvic organ prolpase in the urban population may increase which leads to early detection of the problem and overcome the problem in urban resident populations, as a result the magnitude of POP is lower among women living in urban areas.

The prevalence of POP in this study is higher than the study done in Nepal [31], Nigeria [32], Ghana [33], and rural Pakistan [34]. This might be due to that this study constitutes the pooled result of different community and institutional based research findings.

Furthermore, in comparison with western countries the magnitude of POP in this systematic review and meta-analysis study was higher than reported magnitude among African American women. A study done in US the prevalence of POP was lower in African American women $1.9 \%$ as compared to white women $2.8 \%$ and Hispanic women 5.1\% [29].

In this study, women residing in rural area $(A O R=$ 3.29; $95 \%$ CI: $1.38-7.85)$ were 3.56 times more likely to have POP than the women living in urban areas. This might be justified by the burden of POP in African's people living in United States of America and those residing in Africa comparatively higher number of home deliveries, difficult access to skilled delivery attendance, low attendance of institutional deliveries, lack of awareness on important risk factors, low coverage of family planning, lack of antenatal care follow up, lack of adequate postnatal care follow up with preventive measures, and heavier physical work load among people residing in living Africa predominantly in sub-Saharan Africa [4].

Age $>40$ years $(\mathrm{AOR}=7.43$; 95\% CI: $2.27-24.29)$ is the determinant factor to increase the risk of pelvic organ prolapse. This study finding is consistent with the study done in [35-37]. This might be due to the fact that the risk of POP increases with age because of due to pelvic muscle; ligaments and different pelvic structures are

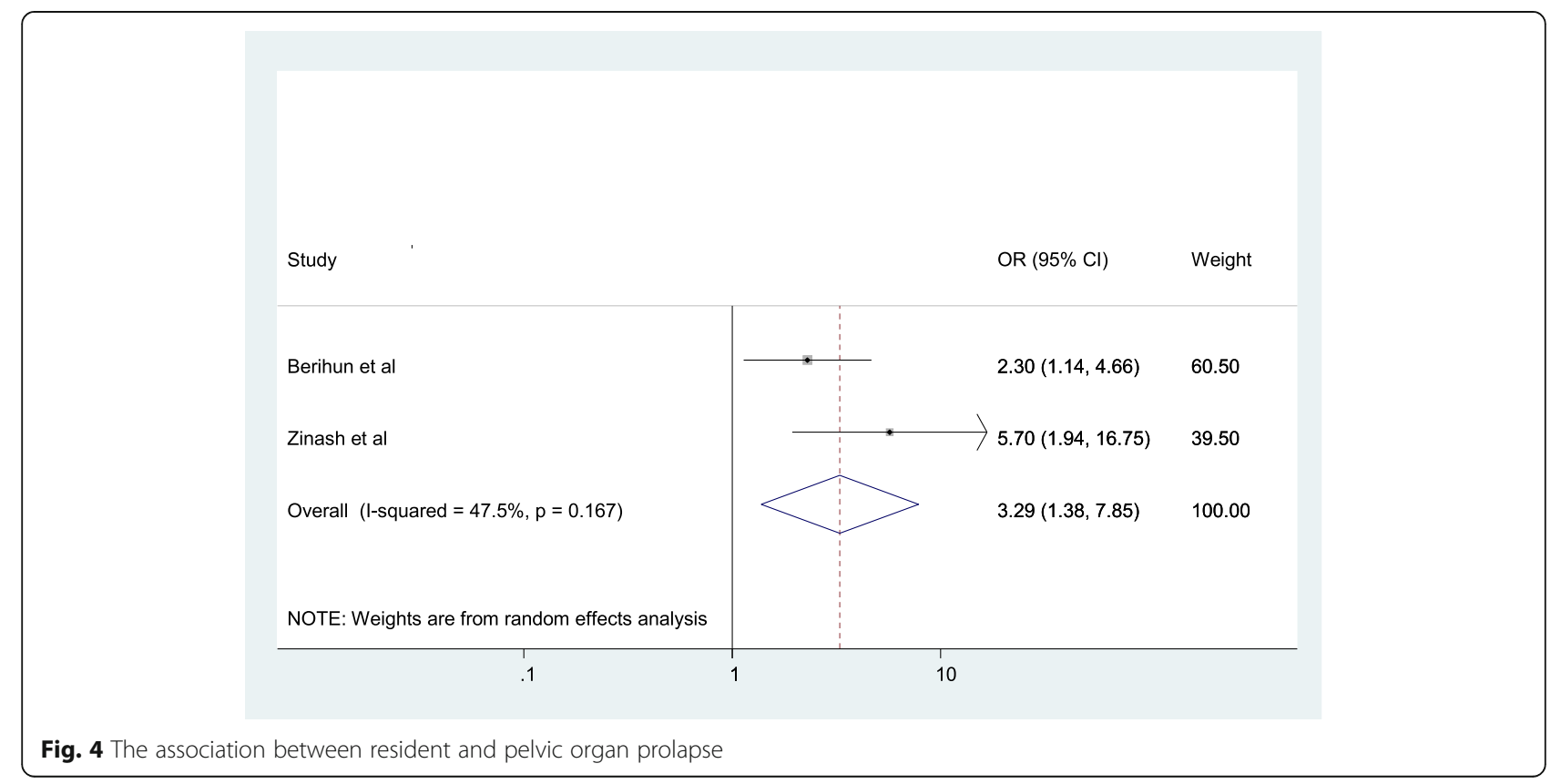




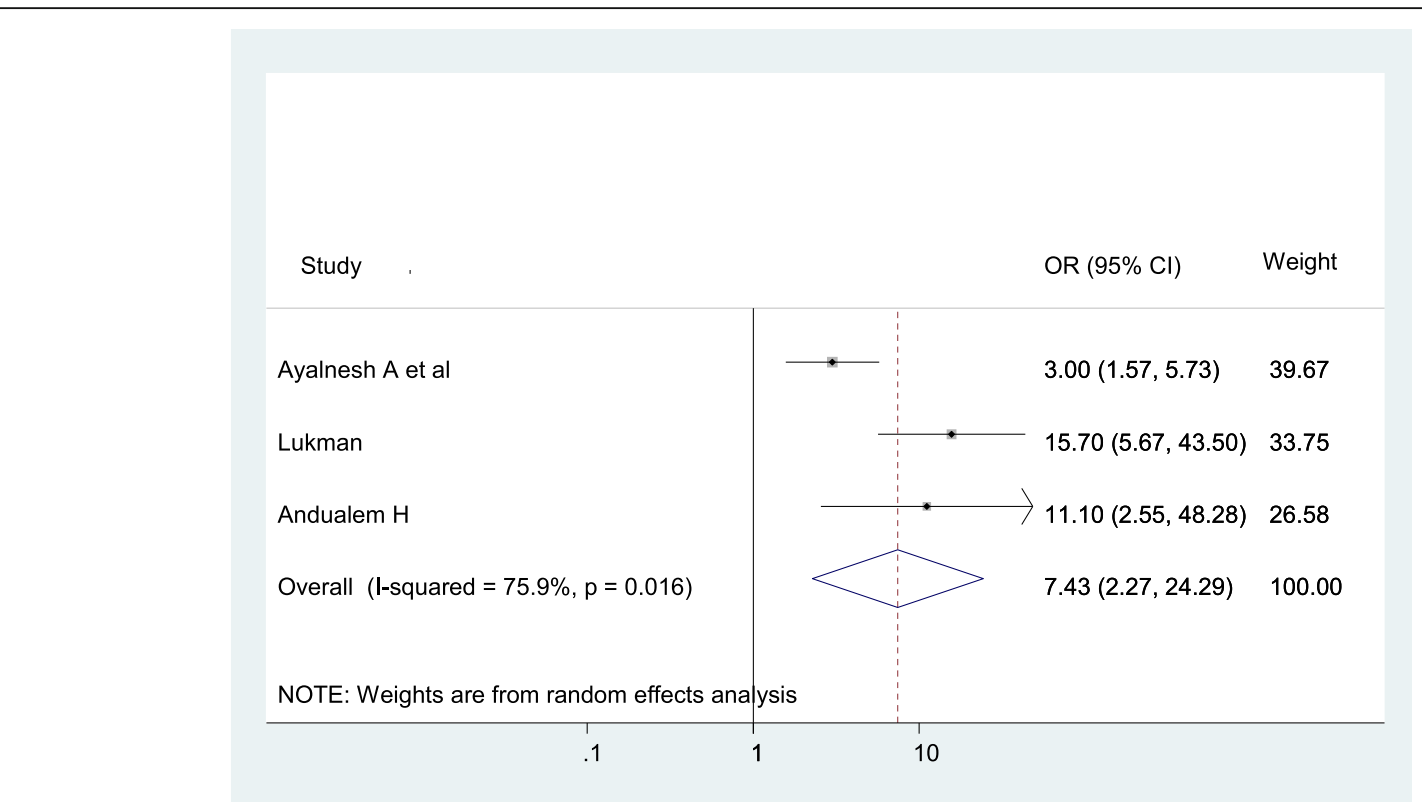

Fig. 5 The association between Age and pelvic organ prolapse

weakening as the age is increasing. As a result of advanced age, the physiological presenation of menopausal women are clearly seen. For example, kyphotic changes due to osteoporosis that developed secondary to advanced age and estrogen deficiency causes a horizontal shift in the pelvic brim which results in reflection of the abdominal contents to the pelvic floor and urogenital hiatus $[38,39]$.

Despite obesity (BMI $25 \mathrm{~kg} / \mathrm{m} 2$ ) could increase the risk of POP, this systematic review and meta-analysis revealed a contrary finding that being underweight (BMI, $18.5 \mathrm{~kg} / \mathrm{m} 2)$ increases the risk of POP threefold $[40,41]$. On the contrary, this systematic review and meta-analysis finding showed that $\mathrm{BMI} \leq 18 \mathrm{~kg} / \mathrm{m}^{2}$ $(\mathrm{AOR}=2.59 ; 95 \%$ CI: $1.53-4.4)$ is increasing the burden of pelvic organ prolapse. While weight gain is a risk factor for developing prolapse, weight loss does not come into sight to be significantly associated with the waning of POP, suggesting that damage to the pelvic floor related to weight gain might be irreversible [42].

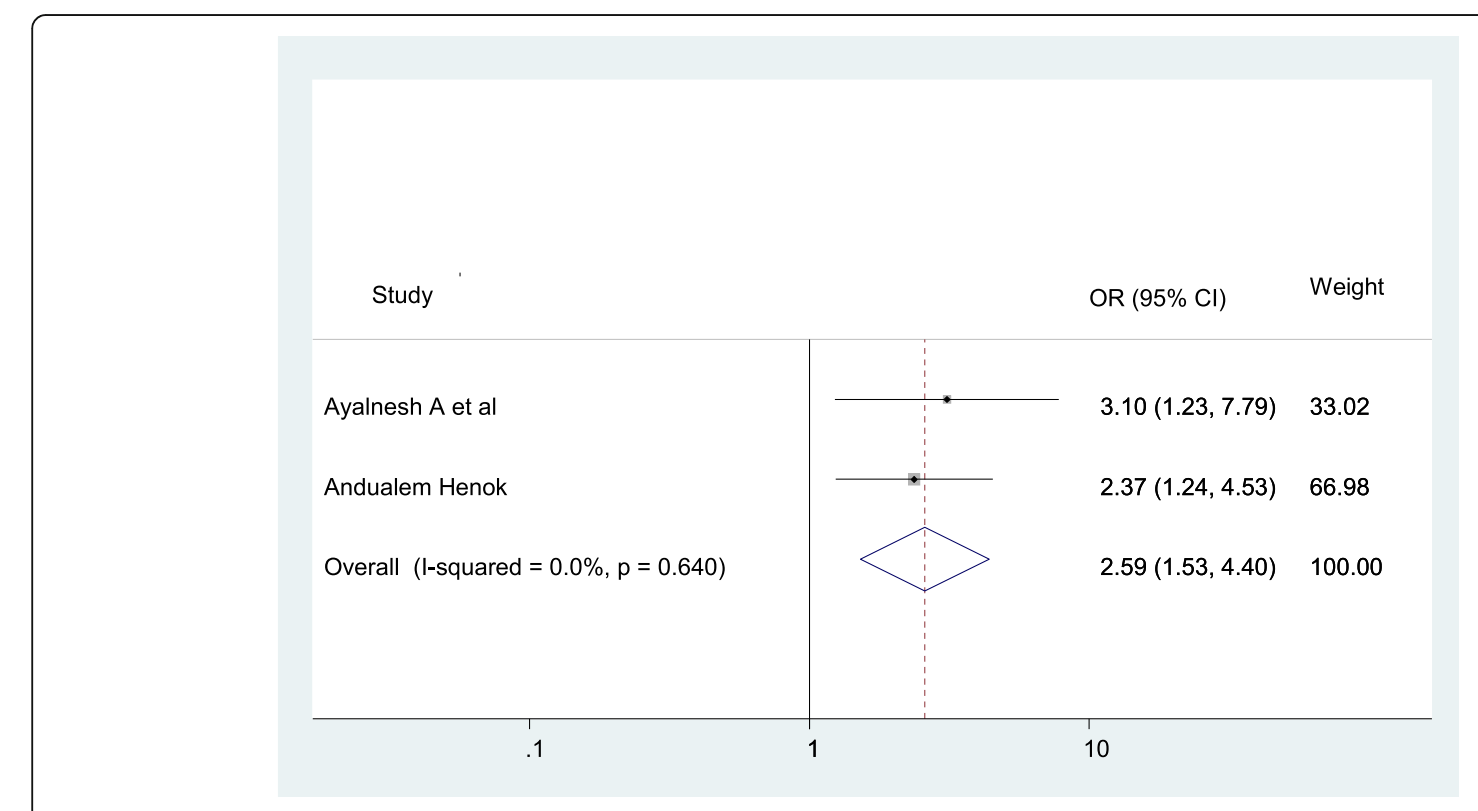

Fig. 6 The association between BMl and pelvic organ prolapse 
Even though the original studies reported, high parity is one of the predictors of POP, estimating odds ratio is difficult since they simply reported the presence of association with chi square. However high parity $(\geq 4)$ increases the risk of POP [33, 40]. This might be due to the fact that repeated pregnancy and birth damages sphincter muscles and ligaments, which sometimes never fully regain its strength and elasticity.

\section{Conclusion}

The pooled prevalence of pelvic organ prolapse was higher. Residence, age and BMI were the predictors of pelvic organ prolpase. Identifying the modified and non modified risk factors for pelvic organ prolpase is a crucial strategic way to prevent further complications and risk of operation.

\section{Supplementary information}

Supplementary information accompanies this paper at https://doi.org/10. 1186/s12905-020-01039-w.

Additional file 1: Table S1. NOS Quality assessment tool for cross sectional and case control studies.

\section{Abbreviations}

AOR: Adjusted Odds Ratio; ANC: Antenatal Care; EDHS: Ethiopia Demographic Health Survey; JBI: Joanna Briggs Institute; POP: Pelvic Organ Prolapse; WHO: World Health Organization

\section{Acknowledgments}

Not applicable.

\section{Authors' contributions}

Both GG and AD critically reviewed, provided substantive feedback and contributed to the intellectual content of this paper and made substantial contributions to the conception, conceptualization and manuscript preparation of this systematic review. All authors read and approved the final manuscript.

\section{Funding}

No funding was obtained for this study.

\section{Availability of data and materials}

The datasets used and/or analyzed during the current study are available from the corresponding author on reasonable request.

Ethics approval and consent to participate

Not applicable.

\section{Consent for publication}

Not applicable.

\section{Competing interests}

All authors declare that they have no competing interests.

Received: 24 January 2020 Accepted: 30 July 2020

Published online: 06 August 2020

\section{References}

1. Haylen BT, de Ridder D, Freeman RM, Swift SE, Berghmans B, Lee J, et al. An international Urogynecological association (IUGA)/international continence society (ICS) joint report on the terminology for female pelvic floor dysfunction. International Urogynecological association, international continence society. Neurourol Urodyn. 2010;29:4-20.
2. Hunskaar S, Lose G, Sykes D, Voss $S$. The prevalence of urinary incontinence in women in four European countries. BJU Int. 2004;93:324-30.

3. Olsen AL, Smith VJ, Bergstrom JO, Colling JC, Clark AL. Epidemiology of surgically managed pelvic organ prolapse and urinary incontinence. Obstet Gynecol. 1997;89:501-6.

4. Nygaard I, et al. Prevalence of symptomatic pelvic floor disorders in US women. JAMA. 2008;300(11):1311-6.

5. Whitcomb EL, Rortveit G, Brown JS, Creasman JM, Thom DH, Van Den Eeden SK, et al. Racial differences in pelvic organ prolapse. Obstet Gynecol. 2009;114:1271-7.

6. Lukacz ES, Lawrence JM, Contreras R, Nager CW, Luber KM. Parity, mode of delivery, and pelvic floor disorders. Obstet Gynecol. 2006;107:1253-60.

7. Subramanian D, Szwarcensztein K, Mauskopf JA, Slack MC. Rate, type, and cost of pelvic organ prolapse surgery in Germany, France, and England. Eur J Obstet Gynecol Reprod Biol. 2009:144:177-81.

8. Vos T, et al. Years lived with disability (YLDs) for 1160 sequelae of 289 diseases and injuries 1990-2010: a systematic analysis for the global burden of disease study 2010. Lancet. 2012;380(9859):2163-96.

9. Walker GJ, Gunasekera P. Pelvic organ prolapse and incontinence in developing countries: review of prevalence and risk factors. Int Urogynecol J. 2011:22(2):127-35.

10. Tehrani FR, Hadhemi S, Simbar SN. Screening of the pelvic organ prolapse without a physical examination; (a community based study). BMC Womens Health. 2011;11:48.

11. Wu JM, Hundley AF, Fulton RG, Myers ER. Forecasting the prevalence of pelvic floor disorders in U.S. women: 2010 to 2050. Obstet Gynecol. 2009; 114:1278-83.

12. Monga A, Dobbs S, editors. Gynaecology by ten teachers. 19th ed. London: Book Power; 2011. p. 154-62.

13. Royal college of obstetrics and gynecology. Pelvic floor disorders, march, 2013.

14. Rogers GR, Villarreal A, Kammerer-Doak D, Qualls C. Sexual function in women with and without urinary incontinence and/or pelvic organ prolapse. Int Urogynecol J. 2001;12:361-5.

15. Lowder JL, Ghetti C, Nikolajski C, Oliphant SS, Zyczynski HM. Body image perceptions in women with pelvic organ prolapse: a qualitative study. Am J Obstet Gynecol. 2011 May;204(5):441

16. Ethiopian Public Health Institute (EPHI) [Ethiopia] and ICF. Ethiopia mini demographic and health survey 2019: key indicators. Rockville: EPHI and ICF; 2019

17. Sendeku, et al. Perinatal asphyxia and its associated factors in Ethiopia. a systematic review and meta-analysis. BMC Pediatr. 2020;20.1:1-11.

18. Rücker G, Schwarzer G, Carpenter JR, Schumacher M. Undue reliance on I 2 in assessing heterogeneity may mislead. BMC Med Res Methodol. 2008;8:79.

19. Nyaga VN, Arbyn M, Aerts M. Metaprop: a Stata command to perform metaanalysis of binomial data. Arch Public Health. 2014;72(1):39.

20. Tsegay B. Epidemiology of utero - vaginal prolapses in Aksum University College of Health Sciences and Comprehensive Specialized Hospital (AKUCHS-CSH), North Ethiopia. Drug intervention today. 12. 7, 2019.

21. Asresie et al, et al. Determinants of pelvic organ prolapse among gynecologic patients in Bahir Dar, north West Ethiopia: a case-control study. Int J Women's Health. 2016.

22. Henok A. Prevalence and factors associated with pelvic organ prolapse among pedestrian BackLoading women in bench Maji zone. Ethiop J Health Sci. 2017;27(3):263.

23. Berihun, et al. Pelvic floor disorders among women in Dabat district, northwest Ethiopia: a pilot study. Int Urogynecol J. 2012

24. Dheresa, et al. One in five women suffers from pelvic floor disorders in Kersa district Eastern Ethiopia: a community-based study. BMC Womens Health. 2018;18:95

25. Menur A, et al. Pelvic organ prolapse in jimma university specialized hospital, southwest ethiopia. Ethiop J Health Sci. 2012;22(2).

26. Lukman Y. Utero-vaginal prolapse: a rural disability of the young. East Afr Med J. 1995:72(1):2-9.

27. Zinash et al. Determinants of pelvic organ prolapse among gynecological cases in wolaita sodo university referral teaching hospital, southern Ethiopia. J Biol Agric Healthcare. Volu 15, No. 21, 2015.

28. Li Z, Xu T, Li Z, Gong J, Liu Q, Wang Y, Wang J, Xia Z, Zhu L. An epidemiologic study of pelvic organ prolapse in postmenopausal women: a population-based sample in China. Climacteric. 2018. https://doi.org/10. 1080/13697137.2018.1520824. 
29. Masenga GG, Shayo BC, Rasch V. Prevalence and risk factors for pelvic organ prolapse in Kilimanjaro, Tanzania: a population based study in Tanzanian rural community. PLoS One. 2018;13(4):e0195910.

30. Scherf C, Morison L, Fiander A, Ekpo G, Walraven G. Epidemiology of pelvic organ prolapse in rural Gambia, West Africa. BJOG. 2002;109:431-6.

31. Safe Motherhood Network Federation Prevalence of Uterine Prolapse amongst Gynecology OPD Patients in Tribhuvan University Teaching Hospital in Nepal and its Socio-Cultural Determinants 2012.

32. Emmanuel C, Ephraim I, Frederick C, Akujiobi C, Chimezie C. Uterovaginal prolapse at a University Teaching Hospital in South-East Nigeria. Orient J Med. 2013;25(3-4):107-12.

33. Wusu-Ansah OK, Opare-Addo HS. Pelvic organ prolapse in rural Ghana. Int J Gynaecol Obstet. 2008;103:121-4.

34. Jokhio AH, rizvi $\mathrm{R} m$. Prevalence of pelvic organ prolapse in women, associated factors and impact on quality of life in rural Pakistan: populationbased study. BMC Womens Health. https://doi.org/10.21203/rs.2.11882/v1.

35. Kim CM, Jeon MJ, Chung DJ, Kim SK, Kim JW, Bai SW. Risk factors for pelvic organ prolapse. Int J Gynecol Obstet, J 2013;24(7):1135-1143. 2007;98(3): 248-251.9.

36. Swift SE, Pound T, Dias JK. Case-control study of etiologic factors in the development of severe pelvic organ prolapse. Int Urogynecol J Pelvic Floor Dysfunct. 2001;12(3):187-92.

37. Swift SE, Tate SB, Nicholas J. Correlation of symptoms with degree of pelvic organ support in a general population of women: what is pelvic organ prolapse? Am J Obstet Gynecol. 2003;189(2):372-7.

38. Moalli PA, Talarico LC, Sung WW, et al. Impact of menopause on collagen subtypes in the arcus tendineous fasciae pelvis. Am J Obstet Gynecol. 2004; 190:620-7.

39. Vardy MD, Lindsay R, Scotti RJ, et al. Short-term urogenital effects of raloxifene, tamoxifen and estrogen. Am J Obstet Gynecol. 2003;189:81-8.

40. Lien YS, Chen GD, Ng SC. Prevalence of and risk factors for pelvic organ prolapse and lower urinary tract symptoms among women in rural Nepal. Int J Gynecol Obstet. 2012;119:185-8.

41. Pradhan S. Unheeded Agonies: a study on uterine prolapse prevalence and it's causes in Siraha and Saptari districts. Kathmandu, Nepal. In: Women's Reproductive Rights programe (WRRP), Center for AgroEcology and Development (CAED); 2007

42. Kudish Bl, Iglesia CB, Sokol RJ, et al. Effect of weight change on natural history of pelvic organ prolapse. Obstet Gynecol. 2009;113:81.

\section{Publisher's Note}

Springer Nature remains neutral with regard to jurisdictional claims in published maps and institutional affiliations.

Ready to submit your research? Choose BMC and benefit from:

- fast, convenient online submission

- thorough peer review by experienced researchers in your field

- rapid publication on acceptance

- support for research data, including large and complex data types

- gold Open Access which fosters wider collaboration and increased citations

- maximum visibility for your research: over $100 \mathrm{M}$ website views per year

At BMC, research is always in progress.

Learn more biomedcentral.com/submissions 